\title{
Suboptimal oral anticoagulant treatment among Chinese non-valvular atrial fibrillation patients: the Nanchang Atrial Fibrillation Project
}

\author{
Qinmei Xiong ${ }^{1,2}$, Alena Shantsila², Juxiang Li $^{1}$, Kui Hong ${ }^{1}$, Gregory Y.H. Lip²
}

\author{
${ }^{1}$ Cardiovascular Department, the Second Affiliated Hospital of Nanchang University, \\ Nanchang, China \\ 2University of Birmingham Centre for Cardiovascular Sciences, City Hospital, \\ Birmingham, United Kingdom
}

Submitted: 12 July 2015

Accepted: 13 July 2015

Arch Med Sci 2016; 12, 1: 216-218

DOI: 10.5114 /aoms.2016.57598

Copyright $\odot 2016$ Termedia \& Banach

When used as thromboprophylaxis in patients with atrial fibrillation (AF), oral anticoagulant (OAC) therapy is effective for preventing stroke and thromboembolism (by 64\%) and all-cause mortality (by 26\%) [1]. Thus, current guidelines recommend OAC in AF patients with $\geq 1$ additional stroke risk factors according to the $\mathrm{CHA}_{2} \mathrm{DS}_{2}$-VASc score. Nevertheless, underuse of OAC is common, but there are limited data on clinical features associated with the non-use of OAC in Asian countries. This is despite the significant burden of AF in Asian countries, which is increasing and numerically larger than that in Western countries [2].

Due to limitations in access to OAC in the nationwide healthcare system in China, we focused on a hospitalized cohort from Nanchang city to provide insights into OAC use (essentially warfarin, given the limited use of novel anticoagulants in China) among patients with non-valvular $\mathrm{AF}$, and to explore the association between clinical characteristics associated with OAC use.

We studied consecutive non-valvular AF patients admitted to the cardiovascular department from May 2011 to December 2013 in the Second Affiliated Hospital of Nanchang University. This is a 2340-bed teaching hospital with 48 attending cardiologists working in the cardiovascular department (15 with an arrhythmia interest). Atrial fibrillation was diagnosed by the attending physician based on an electrocardiogram or Holter monitor. Patients with valvular heart disease requiring surgical management were excluded. Medical records were reviewed to extract data including demographic characteristics, OAC therapy after admission and co-morbidities. The $\mathrm{CHA}_{2} \mathrm{DS}_{2}$-VASc score was calculated to assess the risk of stroke and thromboembolism. Continuous variables, presented as mean \pm standard deviation (SD) or medians and interquartile ranges (IQR), were compared using the $T$-test or Mann-Whitney $U$-test, respectively. Comparisons of categorical variables, presented as $n(\%)$, were undertaken using the $\chi^{2}$ test. Univariate and multivariate logistic regression analyses were performed to evaluate associations between clinical factors and OAC use. All analyses were performed using SPSS 21.0 (Inc., Chicago, IL) and a two-sided $p<0.05$ was considered statistically significant.

The study cohort consisted of 1453 patients (mean age $69.1 \pm 11.2$ years; $44.7 \%$ female), among whom 647 (44.5\%) patients received OAC treatment (i.e., warfarin) after admission. Atrial fibrillation patients tak-

\author{
Corresponding authors: \\ Prof. Gregory Y.H. Lip \\ University \\ of Birmingham Centre \\ for Cardiovascular Sciences \\ City Hospital \\ Birmingham, United Kingdom \\ E-mail: g.y.h.lip@bham.ac.uk \\ Prof. Kui Hong \\ Cardiovascular Department \\ the Second Affiliated Hospital \\ of Nanchang University \\ Nanchang, China \\ Phone: +44 1215075080 \\ Fax: +44 1215544083 \\ E-mail: hongkui88@163.com
}


ing warfarin were younger than those not taking warfarin $(p<0.001)$ (Table I). The proportions of patients receiving warfarin significantly decreased with increasing age, with only $36.7 \%$ of warfarin users among patients aged $\geq 75$ years. There were no significant differences in subtype of $A F$ or $\mathrm{CHA}_{2} \mathrm{DS}_{2}$-VASC score between warfarin users and non-users. Among high-risk patients with a $\mathrm{CHA}_{2} \mathrm{DS}_{2}$-VASc score $\geq 2$ in males or $\geq 3$ in fe- males, only $45.1 \%$ of patients received warfarin therapy after admission.

Univariate analysis shows that warfarin use was negatively associated with age $\geq 75$ years and concomitant coronary artery disease, but positively related to prior stroke/transient ischemic attack (TIA)/thromboembolism (TE), history of hypertension and diabetes mellitus (Table II). On multivariate analysis, predictors of warfarin

Table I. Patient characteristics categorized by warfarin use

\begin{tabular}{|c|c|c|c|c|}
\hline Parameter & $\begin{array}{l}\text { All patients } \\
(n=1453)\end{array}$ & $\begin{array}{c}\text { On-warfarin } \\
(n=647)\end{array}$ & $\begin{array}{c}\text { Non-warfarin } \\
(n=806)\end{array}$ & $P$-value \\
\hline Female & $649(44.7)$ & $301(46.5)$ & $348(43.2)$ & 0.203 \\
\hline \multicolumn{5}{|l|}{ Age [years]: } \\
\hline Mean \pm SD & $69.1 \pm 11.2$ & $67.7 \pm 10.8$ & $70.2 \pm 11.4$ & $<0.001$ \\
\hline$<40$ & $17(1.2)$ & $9(52.9)$ & $8(47.1)$ & \multirow[t]{4}{*}{$<0.001$} \\
\hline $40-64$ & $428(29.5)$ & $213(49.8)$ & $215(50.2)$ & \\
\hline $65-74$ & $474(32.6)$ & $229(48.3)$ & $245(51.7)$ & \\
\hline$\geq 75$ & $534(36.8)$ & $196(36.7)$ & $338(63.3)$ & \\
\hline \multicolumn{5}{|c|}{ Blood pressure on admission, $n=1443^{*}$ (641 on-warfarin), mean $\pm \mathrm{SD}[\mathrm{mm} \mathrm{Hg}]$} \\
\hline SBP & $129.9 \pm 21.0$ & $129.9 \pm 20.5$ & $130.0 \pm 21.4$ & 0.897 \\
\hline DBP & $77.7 \pm 12.6$ & $78.1 \pm 12.1$ & $77.5 \pm 13.0$ & 0.373 \\
\hline \multicolumn{5}{|c|}{ LVEF, $n=1261^{*}$ (575 on-warfarin): } \\
\hline Mean \pm SD & $57.8 \pm 12.1$ & $57.9 \pm 12.2$ & $57.8 \pm 12.1$ & 0.916 \\
\hline$<55 \%$ & $416(33.0)$ & $192(46.2)$ & $224(53.8)$ & \multirow[t]{2}{*}{0.810} \\
\hline$\geq 55 \%$ & $845(67.0)$ & $383(45.3)$ & $462(54.7)$ & \\
\hline \multicolumn{5}{|l|}{ Type of atrial fibrillation: } \\
\hline Paroxysmal & $316(21.7)$ & $133(42.1)$ & $183(57.9)$ & \multirow[t]{2}{*}{0.338} \\
\hline Persistent/Permanent & $1137(78.3)$ & $514(45.2)$ & $623(54.8)$ & \\
\hline \multicolumn{5}{|l|}{$\mathrm{CHA}_{2} \mathrm{DS}_{2}$-VASc score: } \\
\hline Median (IQR) & $3(2-4)$ & $3(2-4)$ & $3(2-4)$ & 0.942 \\
\hline Male $=0$ or female $=1$ & $138(9.5)$ & $78(43.5)$ & $60(56.5)$ & \multirow[t]{3}{*}{0.777} \\
\hline Male $=1$ or female $=2$ & $257(17.7)$ & $110(42.8)$ & $147(57.2)$ & \\
\hline Male $\geq 2$ or female $\geq 3$ & $1058(72.8)$ & $477(45.1)$ & $581(54.9)$ & \\
\hline
\end{tabular}

$\mathrm{CHA}_{2} \mathrm{DS}$-VASC - congestive heart failure, hypertension, age $\geq 75$ years (double), diabetes mellitus, stroke/transient ischemic stroke/ thromboembolism history (double), vascular disease, age (65-74), sex (female), DBP - diastolic blood pressure, IQR - interquartile range, $L V E F$ - left ventricular ejection fraction, SBP-systolic blood pressure, SD - standard deviation; *the number of patients with available data.

Table II. Clinical predictors associated with warfarin use

\begin{tabular}{|lcccc|}
\hline \multirow{2}{*}{ Parameter } & \multicolumn{2}{c}{ Univariate analysis } & \multicolumn{2}{c|}{ Multivariate analysis } \\
\cline { 2 - 5 } & OR $(95 \% \mathrm{CI})$ & $P$-value & OR $(95 \% \mathrm{Cl})$ & $P$-value \\
\hline Age $\geq 75$ years & $0.60(0.48-0.75)$ & $<0.001$ & $0.54(0.43-0.69)$ & $<0.001$ \\
\hline Gender, female & $1.15(0.93-1.41)$ & 0.202 & $1.12(0.90-1.39)$ & 0.317 \\
\hline Heart failure & $0.99(0.80-1.21)$ & 0.902 & $1.12(0.90-1.39)$ & 0.305 \\
\hline Hypertension & $1.34(1.08-1.65)$ & 0.007 & $1.43(1.14-1.79)$ & 0.002 \\
\hline Diabetes & $1.47(1.04-2.11)$ & 0.031 & $1.43(0.99-2.07)$ & 0.056 \\
\hline Prior stroke/TIA/TE & $1.55(1.15-2.07)$ & 0.004 & $1.59(1.18-2.16)$ & 0.003 \\
\hline Coronary artery disease & $0.60(0.47-0.77)$ & $<0.001$ & $0.62(0.48-0.80)$ & $<0.001$ \\
\hline Peripheral artery disease & $0.15(0.02-1.24)$ & 0.079 & $0.15(0.02-1.24)$ & 0.078 \\
\hline
\end{tabular}

Cl - confidence interval, OR - odds ratio, TE - thromboembolism, TIA - transient ischemic attack. 
use during hospital admission were hypertension (odds ratio (OR) 1.43; 95\% confidence interval (CI) 1.14-1.79, $p=0.002$ ) and prior stroke/TIA/TE $(\mathrm{OR}=1.59 ; 95 \% \mathrm{Cl}: 1.18-2.16, p=0.003)$, whilst age $\geq 75$ years $(\mathrm{OR}=0.54 ; 95 \% \mathrm{Cl}: 0.43-0.69$, $p<0.001)$ and coronary artery disease $(\mathrm{OR}=0.62$; $95 \% \mathrm{Cl}: 0.48-0.80, p<0.001)$ were independently associated with less frequent warfarin use (Table II).

The use of warfarin was very low in previous community-based Chinese cohort studies [3, 4]. With the awareness of the importance of OAC therapy in AF management, warfarin prescription has increased recently, but it still remains under-prescribed. The present study demonstrates suboptimal warfarin use in hospitalized patients with non-valvular AF. Importantly, age $\geq 75$ years was a predictor of non-use of warfarin in our Chinese cohort, which is consistent with prior data from China [5]. Elderly patients with non-valvular AF have a relatively high risk of both ischemic stroke and major bleeding [6], but the benefits of warfarin over aspirin (or non-treatment) have been evident from observational cohorts and trials [7]. In the Birmingham Atrial Fibrillation Treatment of the Aged (BAFTA) trial, for example, warfarin was superior to aspirin for the prevention of thromboembolism among elderly AF patients aged $\geq 75$ years, with no significant difference in major bleeding or intracranial haemorrhage [8].

Additionally, we found that concomitant coronary artery disease had a negative impact on warfarin use. This is perhaps due to AF patients with coronary artery disease being co-treated with antiplatelet agents. This combination therapy of warfarin and antiplatelet would increase bleeding risks. Also, the older $\mathrm{CHADS}_{2}$ scoring system is widely used in China to guide decisions on thromboprophylaxis, in which vascular disease was not considered as a risk factor for stroke among AF patients. The reason for the use of warfarin in many low-risk patients could be due to the catheter radiofrequency ablation. Two positive predictors of warfarin use in this cohort were hypertension and prior stroke/TIA/TE, which are both risk factors for ischemic stroke among patients with non-valvular AF. Hypertension is clearly a strong stroke risk factor among Chinese cohorts [9], as is prior stroke/TIA/TE.

In conclusion, warfarin use is suboptimal in Chinese hospitalized AF patients, even among highrisk individuals (i.e., $\mathrm{CHA}_{2} \mathrm{DS}_{2}$-VASc score $\geq 2$ ). Age $\geq 75$ years and presence of coronary artery disease are negative predictors of warfarin use. Interventions to improve arrhythmia awareness and effective stroke prevention with OAC in China are urgently needed.

\section{Acknowledgments}

Kui Hong and Gregory Y.H. Lip - joint senior authors.

\section{Conflicts of interest}

Prof Lip has served as a consultant for Bayer, Merck, Sanofi, BMS/Pfizer, Daiichi-Sankyo, Biotronik, Medtronic, Portola and Boehringer Ingelheim and has been on the speakers' bureau for Bayer, BMS/Pfizer, Boehringer Ingelheim, Daiichi-Sankyo, and Medtronic. Other authors - none declared.

\section{References}

1. Hart RG, Pearce LA, Aguilar MI. Meta-analysis: antithrombotic therapy to prevent stroke in patients who have nonvalvular atrial fibrillation. Ann Intern Med 2007; 146: 857-67.

2. Tse HF, Wang YJ, Ahmed Ai-Abdullah M, et al. Stroke prevention in atrial fibrillation: an Asian stroke perspective. Heart Rhythm 2013; 10: 1082-8.

3. Zhang X, Zhang S, Li Y, et al. Association of obesity and atrial fibrillation among middle-aged and elderly Chinese. Int J Obes 2009; 33: 1318-25.

4. Zhou Z, Hu D. An epidemiological study on the prevalence of atrial fibrillation in the Chinese population of mainland China. J Epidemiol 2008; 18: 209-16.

5. Guo Y, Pisters R, Apostolakis S, et al. Stroke risk and suboptimal thromboprophylaxis in Chinese patients with atrial fibrillation: would the novel oral anticoagulants have an impact? Int J Cardiol 2013; 168: 515-22.

6. Lip GY, Clementy N, Pericart L, Banerjee A, Fauchier L. Stroke and major bleeding risk in elderly patients aged $>/=75$ years with atrial fibrillation: the Loire Valley atrial fibrillation project. Stroke 2015; 46: 143-50.

7. Marinigh R, Lip GY, Fiotti N, Giansante C, Lane DA. Age as a risk factor for stroke in atrial fibrillation patients: implications for thromboprophylaxis. J Am Coll Cardiol 2010; 56: 827-37.

8. Mant J, Hobbs FD, Fletcher $\mathrm{K}$, et al. Warfarin versus aspirin for stroke prevention in an elderly community population with atrial fibrillation (the Birmingham Atrial Fibrillation Treatment of the Aged Study, BAFTA): a randomised controlled trial. Lancet 2007; 370: 493-503.

9. Huang D, Anguo L, Yue WS, Yin L, Tse HF, Siu CW. Refinement of ischemic stroke risk in patients with atrial fibrillation and CHA2DS2-VASc score of 1. Pacing Clin Electrophysiol 2014; 37: 1442-7. 